\section{Fatores de risco associados à infecção pelo vírus da hepatite $\mathrm{C}$}

Com o objetivo de avaliar os fatores de risco associados à infecção pelo vírus da hepatite $\mathrm{C}$, principalmente aqueles relacionados ao comportamento sexual, desenvolveu-se um estudo do tipo caso-controle, onde a população estudada foi a dos doadores da Fundação Pró-Sangue Hemocentro de São Paulo. Os doadores de sangue envolvidos no estudo foram submetidos a uma entrevista e a exames laboratoriais, e de acordo com os resultados destes últimos, foram classificados em casos e controles. A entrevista avaliou variáveis relacionadas ao comportamento sexual, como número de parceiros, tipo de parceiros (regulares, casuais ou prostitutas), tipo de relação sexual (vaginal e anal), uso de preservativos, antecedente de doença sexualmente transmissível, antecedentes de transfusão e de uso de droga injetável do parceiro, e outras variáveis como antecedente de transfusão de sangue, de uso de droga injetável, de internação hospitalar, de cirurgia, de tatuagem e de acupuntura do entrevistado. Os exames laboratoriais constaram de dosar anticorpos contra o vírus da hepatite $\mathrm{C}$ pelo método imunoenzimático e pelo método recombinante imunoblot, ambos testes de segunda geração. Estudou-se também a presença de HCV RNA pela reação em cadeia de polimerase tipo "nested". Estimou-se também a freqüência de parceiros com anticorpos contra o vírus da hepatite $\mathrm{C}$ em parceiros dos casos. Foram considerados fatores de risco independentes para a infecção pelo vírus da hepatite $\mathrm{C}$ : antecedente de doença sexualmente transmissível (OR 2,35; IC 95\% 1,14 4,82), de homossexualismo (OR 5,56; IC 95\% 1,60 10.39), parceria com prostitutas (OR 2,77; IC $95 \%$ $1,32-5,79)$, parceria sexual com hemotransfundido (OR 5,72; IC 95\% 1,89 - 17,35), antecedente de transfusão de sangue (OR 12,21; IC 95\% 5,40 27,64 ), de tatuagem (OR 6,30; IC 95\% 2,00 - 19,83) e o nível educacional foi considerado como fator de proteção $\left(\chi^{2}\right.$ de tendência $\left.4,62, p=0,032\right)$. De 68 parceiros sexuais dos casos estudados, $8(11,76 \%)$ tiveram exames laboratoriais compatíveis com infecção pregressa ou atual pelo vírus da hepatite C.

\section{Risk factors associated to hepatitis $\mathrm{C}$ virus infection}

\author{
In order to evaluate the risk factors
} associated to hepatitis $C$ virus, mainly those related to sexual behaviour, a case control study was developed: blood donors from Fundação PróSangue Hemocentro de São Paulo were invite to participate. The blood donors who agreed to participate were interviewed and laboratory tests were performed. Depending on those results, they were classified as cases and controls. The blood donors were asked about number of partners, type of partners (regular, casual or prostituts), type of sexual intercourse (vaginal or anal), condom use, previous sexually transmitted disease, homosexuality, previous intravenous drug user partner and also about other variables: previous blood transfusion, hospitalization, surgery, tatooing and acupuncture. Antibodies against hepatitis $C$ virus were tested, using second generation enzyme linked immunoassay and recombinant immunoblot assay. HCV RNA was tested, using "nested" polymerase chain reaction. The frequency of cases partners with antibodies against hepatitis $C$ virus was evaluated, too. The risk factors considered to be independent were: previous S (OR 2.35; Cl 95\% 1.14-4.82), homosexuality (OR 5.56; Cl 95\% 1.6019.39), sexual partner who had received blood transfusion (OR 5.72; Cl 95\% 1.32-5.79), prostituts partners (OR 2.77; Cl 95\% 1.32-5.79), and previous blood transfusion. Educational level was considered as a protector factor ( $\chi^{2}$ trend 4.62 $p=0.032)$. Eight $(11.76 \%)$ of 68 cases partners had laboratorial tests compatible with previous or current hepatitis $\mathrm{C}$ virus infection.

Fátima Mitiko Tengan

Tese apresentada à Faculdade de Medicina da

Universidade de São Paulo para obtenção

do Título de Doutor.

São Paulo, SP, Brasil, 1997.

Recebido para publicação em 06/04/98. 